\title{
Adenomyosis: correlating clinical suspicion with histopathological diagnosis in a retrospective study
}

\author{
Preet Kamal, Ripan Bala*, Madhu Nagpal, Harleen Kaur
} Department of Obstetrics and Gynecology, Sri Guru Ram Das Institute of Medical Sciences and Research, Vallah,
Amritsar, Punjab, India

Received: 24 October 2019

Accepted: 12 November 2019

\section{*Correspondence:}

Dr. Ripan Bala,

E-mail: ripanchanana@yahoo.co.in

Copyright: (c) the author(s), publisher and licensee Medip Academy. This is an open-access article distributed under the terms of the Creative Commons Attribution Non-Commercial License, which permits unrestricted non-commercial use, distribution, and reproduction in any medium, provided the original work is properly cited.

\section{ABSTRACT}

Background: Adenomyosis and leiomyoma are the common causes of abnormal uterine bleeding (AUB). In this study it is aimed to evaluate the correlation of clinical and histopathological examination (HPE) of these entities leading to abnormal uterine bleeding.

Methods: This retrospective study was carried out on hysterectomy specimens of subjects who presented themselves in the department of obstetrics and gynaecology of Sri Guru Ram Das Institute of medical sciences and research, Amritsar with chief complaints of AUB not responding to conservative treatment.

Results: A total of 100 women with clinical diagnosis of AUB in which hysterectomies were performed, leiomyoma was found in $42 \%$ cases, adenomyosis in $22 \%$ cases. The most frequent combination of diagnosis was leiomyoma and adenomyosis i.e. $26 \%$. In $9 \%$ cases chronic cervicitis and ovarian cyst were detected. In one case endometrial malignancy was found.

Conclusions: Though adenomyosis and leiomyoma are clinically diagnosed along with other pathological conditions of the reproductive organs, but their confirmation is still to be relied upon HPE; a most important investigation.

Keywords: Abnormal uterine bleeding, Adenomyosis, Histopathological examination, Hysterectomy, Leiomyoma

\section{INTRODUCTION}

Menstrual disturbances are the common presentation in women in their reproductive age group. Uterine myomas, adenomyosis, polyp, endometrial hyperplasia and malignancy are the structural causes of AUB. To diagnose the causative factors of AUB along with history taking and clinical examination age and need related preliminary to advance investigations are required ranging from routine preoperative investigations, pap smear ultrasonography, three dimensional transvaginal ultrasound, colour doppler, MRI, hysterosalpingography, dilatation and curettage, hysteroscopy, diagnostic laparoscopy and in few cases intravenous urography. ${ }^{1}$ Option of treatment changes with age and symptoms.
Younger patients' complaints of dysmenorrhoea alone and moreover they desire fertility. Whereas middle age group patients who have severe symptomatology, in them treatment varies depending upon tolerance to symptoms. The main stay of treatment in such cases had been hysterectomy which still remains widely practiced and is the treatment if choice, but it should be our endeavour to manage such cases conservatively i.e. hysterectomy should be last resort. Estimation of the prevalence of adenomyosis varies widely from $5 \%-70 \%$ which is probably related to inconsistencies in histopathological criteria for diagnosis. ${ }^{2}$ On contrary, leiomyoma is having high prevalence up to $70 \%$ in Caucasians and $80 \%$ in women of African ancestry. ${ }^{3}$ 
The purpose of present study was to find the prevalence of adenomyosis and leiomyoma as a cause of AUB in the Amritsar region of Punjab by clinical and HPE of the uterus removed as a treatment option of AUB. Inconsistencies in the clinical and histopathological findings will be evaluated thereby knowing the role of histopathology in the confirmation of final diagnosis.

\section{METHODS}

A retrospective analytic study (research methodology) of 100 patients (study population) who reported in the obstetrics and gynecology department Sri Guru Ram Das Institute of Medical Sciences and Research from Amritsar region of Punjab w.e.f. January 2015 to December 2016 (study period) with history of abnormal uterine bleeding in whom hysterectomies were done were studied after analysing and interpretaing their indoor record (by applying inferential statistics analysis method). Only those cases were included (inclusion criteria) who were in the perimenopausal age group, whereas patients with history of abnormal uterine bleeding and diagnosed as carcinoma of uterus were excluded (exclusion criteria). The patient's age, presenting symptoms and ultrasonography findings were studied. The inconsistency between the clinical suspicion and their correlation with the HPE reports were studied.

\section{RESULTS}

In the present study of100 cases ranging from 21-70 years of age in which hysterectomies performed were studied. Clinically, the maximum no. (64\%) of cases were in the age range of 41 to 50 years and least in the age group of 21 to 30 years. 16 cases of different pathology i.e. malignancy, chronic cervicitis and ovarian cysts in different age group were diagnosed clinically as per Table 1 . No case in the age group of 60-70 years with history of AUB was reported. Preoperative diagnosis of AUB due to various causes in different age groups were as per Table 1 .

Only one case of leiomyoma was confirmed in the in the age group of 21 to 30 years and $59 \%$ of various pathologies were confirmed in the age group of 410-50 years as per Table 2 .

A total $61 \%$ cases of leiomyoma which were preoperatively diagnosed (Table 1) were actually $42 \%$ as per HPE (Table 2). Dual pathology i.e. adenomyosis and leiomyoma were found in $26 \%$. As per Table 2, $9 \%$ cases were in the category of other pathologies comprising of chronic cervicitis and ovarian cysts. One case was of endometrial carcinoma.

As per Table 3, only confirmed cases of Adenomyosis and Leiomyoma have been depicted whereas combined diagnosis of these pathologies i.e. Adenomyosis and leiomyoma histopathologically were found in 48 and 68 cases.

As per Table 4, history of heavy menstrual bleeding was found in $73 \%$ cases of combined pathology and maximally in leiomyoma cases $(67 \%)$.

Out of 100 studied cases $40 \%$ presented with dysmenorrhoea and in $20 \%$ cases pain and pressure symptoms were detected. In $75 \%$ cases of adenomyosis, dysmenorrhoea was the main complaint. Pain and pressure symptoms were the main findings in leiomyoma $(75 \%)$.

Table 1: Distribution of cases of suspected pathology in different age groups (preoperatively).

\begin{tabular}{|lllll|}
\hline Age group (years) & Adenomyosis & Leiom-yoma & Other pathology & Total \\
\hline $21-30$ & - & 1 & - & 1 \\
\hline $31-40$ & 5 & 17 & 1 & 23 \\
\hline $41-50$ & 17 & 37 & - & 54 \\
\hline $51-60$ & 1 & 6 & - & 7 \\
\hline $61-70$ & - & - & $\mathbf{1}$ & - \\
\hline Total & $\mathbf{2 3}$ & $\mathbf{6 1}$ & $\mathbf{8 5}^{*}$ & \\
\hline
\end{tabular}

*As per Table 1, out of 100 cases in 15 cases of AUB no clinical cause of AUB was detected but hysterectomies were done to relieve the distressed patients of their symptomatology. One case reported in other pathology in the age group of 31- 40 years was of endometrial malignancy.

Table 2: Distribution of cases of confirmed pathology in different age groups (HPE).

\begin{tabular}{|llllll|}
\hline Age group (years) & Adenomyosis & Leiomyoma & Dual & Others & Total \\
\hline $21-30$ & - & 1 & - & 1 & 2 \\
\hline $31-40$ & 2 & 15 & 6 & 4 & 27 \\
\hline $41-50$ & 17 & 23 & 16 & 3 & 59 \\
\hline $51-60$ & 3 & 3 & 4 & 2 & 12 \\
\hline $61-70$ & - & - & - & - & - \\
\hline Total & $\mathbf{2 2}$ & $\mathbf{4 2}$ & $\mathbf{2 6}$ & $\mathbf{1 0}$ & $\mathbf{1 0 0}$ \\
\hline
\end{tabular}


Table 3: Correlation of histopathological diagnosis with the clinical diagnosis.

\begin{tabular}{|lll|}
\hline Lesions & No. of cases diagnosis preoperatively & No. of cases confirmed histopathologically \\
\hline Adenomyosis & 23 & 48 \\
\hline Leiomyoma & 61 & 68 \\
\hline
\end{tabular}

Table 4: Correlation of histopathological lesions with type of bleeding in AUB.

\begin{tabular}{|llll|}
\hline Type of AUB & Adenomyosis & Leiomyoma & Dual pathology \\
\hline HMB & 16 & 49 & 8 \\
\hline IMB & 9 & 11 & 5 \\
\hline Both HMB and IMB & 4 & 5 & 4 \\
\hline
\end{tabular}

Table 5: Correlation of histopathological lesions with the presenting symptoms.

\begin{tabular}{|lllll|}
\hline Presenting symptoms & No. of cases & Adenomyosis & Leiomyoma & Dual pathology \\
\hline Dysmenorrhoea & 40 & 30 & - & 10 \\
\hline Pain and pressure symptoms & 20 & - & 15 & 5 \\
\hline
\end{tabular}

\section{DISCUSSION}

In the present study, 59\% of the patients with AUB belonged to the age group of 41-50 years. Leiomyoma was the most common cause of AUB (42\%) which is more or less alike incidence reported by Sajjad et al, Sarfraz et al, Tahira et al, and Khawja et al. ${ }^{4-7}$ In all these studies similar to the present study, leiomyoma has been reported as the commonest pathological lesion in patients of AUB. The clinical diagnosis of Adenomyosis preoperatively was done in $23 \%$ cases whereas with the HPE it was detected $48 \%$ which is in line with the incidence reported by Gerson et al and Bird et al. ${ }^{8,9}$ So the strong clinical suspicion about the presence of adenomyosis in these cases led to the histopathological investigation ascertaining the diagnosis of adenomyosis. So, the authors do not hesitate in opining that adenomyosis still remains the histopathological diagnosis. The different type of bleeding reported by patients and their other presenting symptoms (Table 4, 5) have also been reported by Hoffman, et al, Berek et al. ${ }^{10,11}$ Underdiagnoses of adenomyosis (Table 3) as compared to confirmed histopathological diagnosis lays emphasis on the optimum utilization of imaging tool (MRI) which could have diagnosed it earlier.

\section{CONCLUSION}

Though ultrasonography helps in diagnosing and differentiating between leiomyoma and adenomyosis preoperatively but the main stay of confirmation of diagnosis lies with the HPE especially adenomyosis which still remains a clinical challenge. Even then, the possibilities of both the lesions should be kept in mind by the clinician while managing cases of AUB. Latest conservative treatment of AUB and its prohibitive cost compels a patient to choose hysterectomy as a mode of treatment.
Now with the advent of better imaging tools and conservative methods (medical and surgical) and their availability in the hands of experts, need to be propagated. Menstrual disturbances are annoying and patients opt for removal of uterus at the edge of menopausal symptoms.

Funding: No funding sources Conflict of interest: None declared

Ethical approval: The study was approved by the Institutional Ethics Committee

\section{REFERENCES}

1. Dueholm M. Transvaginal ultrasound for diagnosis of adenomyosis: a review. Best Pract Res Clin Obstet Gynaecol. 2006;20:569-82.

2. Azziz R. Adenomyosis: current perspectives. Obstet Gynecol Clin North Am. 1989;16:221-35.

3. Baird DD, Dunson DB, Hill MC, Cousins D, Schectman JM. High cumulative incidence of uterine leiomyoma in black and white women: Ultrasound evidence. Am J Obstet Gynecol. 2003;188:100-7.

4. Sajjad M, Iltaf S, Qayyum S. Pathological findings in Hysterectomy specimens of patients presenting with menorrhagia in different age groups. Ann Pak Inst Med Sci. 2011;7:160-2.

5. Sarfraz T, Tariq H. Histopathologic findings in menorrhagia a study of 100 hysterectomy specimens. Pak J Pathol. 2005;16:83-5.

6. Tahiira T, Qureshi S, Roohi M. Abdominal hysterectomy; performed by post graduate trainees. Professional Med J. 2007;14:685-8.

7. Khawaja N, Zahid B, Tayyeb R. Clinical audit of hysterectomies. Ann King Edward Med Coll. 2005;11:219-21.

8. Gerson W, Priya M, Laura LS, Sarah EB, Miriam S, Janet MJ. Adenomyosis a variant not a disease? 
Evidence from hysterectomized menopausal women in the SWAN study. Fertil Steril. 2009;91(1)201-6.

9. Bird CC, McElin TW, Manalo-Estrella P. The elusive adenomyosiso the uterus-revisited. Am J Obstet Gynecol. 1972;112:583-93.

10. Hoffman BL. Williams Gynecology. $2^{\text {nd }}$ ed. Mc Graw Hill, San Francisco; 2012:219-40.
11. Berek JS, Berek DL.16 ${ }^{\text {th }}$ Ed. Berek and Novak's Gynaecology. Lippincott Williams and Wilkins. Philadelphia; 2019:461-467.

Cite this article as: Kamal $\mathrm{P}$, Bala R, Nagpal M, Kaur H. Adenomyosis: correlating clinical suspicion with histopathological diagnosis in a retrospective study. Int J Reprod Contracept Obstet Gynecol 2019;8:4674-7. 